\title{
Preliminary study of passengers' body heat harvesting potential in commercial transport aircraft
}

\begin{abstract}
The increasing demands for onboard electrical power of commercial transport aircraft have driven the search for other alternative power sources instead of relying only on the propulsion system. Along with the motivation for renewable and greener energy usage, heat energy harvesting from the passengers' body while they are seated has been proposed to generate electrical power for the seat's electronics. This heat energy harvesting concept uses thermoelectric devices that convert energy potential from temperature difference into electrical power based on the phenomenon known as Seebeck effects. The generated electrical power from this method heavily depends on the temperature gradient between the two sides of the thermoelectric generator. Therefore, this study has been made to demonstrate the potential of energy harvesting from the dissipated body heat of the seated aircraft passengers. Overall, based on 20 conducted experimental cases, it has been found out that the average maximum temperature that can be possibly obtained from the passengers' dissipated body heat is about $35.5^{\circ} \mathrm{C}$. This leads to a maximum temperature difference between the seated passengers' body and the cabin environment of about $15.5^{\circ} \mathrm{C}$, which can be converted into about $10.23 \mathrm{~mW}$ of electrical power per each sensor point in the experiment using a standard thermoelectric generator.
\end{abstract}

Keyword: Heat energy; Body heat; Aircraft passengers; Thermoelectric; Energy harvesting 